\title{
PENGARUH EXPERIENTIAL MARKETING DAN ZOO IMAGE TERHADAP REVISIT INTENTION DENGAN EXPERIENTIAL SATISFACTION SEBAGAI VARIABEL INTERVENING
}

\author{
Viyo Tri Taraoktavia \\ Universitas Negeri Surabaya \\ viyotaraoktavia16080574117@mhs.unesa.ac.id \\ Tias Andarini Indarwati \\ Universitas Negeri Surabaya \\ tiasindarwati@unesa.ac.id
}

\begin{abstract}
The sustainability of a tourist attraction is reflected by the experiential satisfaction of visitors to tourism objects. One of the influencing factors is to create engaging experiential marketing and make an impression on the visitor's mind and the image attached to the company. Experiencing engaging experiential marketing and a good image from the company makes visitors feel experiential satisfaction and revisit intention. This study aims to determine the effect of experiential marketing and zoo image on revisit intention with experiential satisfaction as an intervening variable. This study used 200 samples with a non-probability sampling technique using the purposive sampling method. Data were collected using an online questionnaire. The analytical tool in this research is path analysis using AMOS and IBM SPSS. Based on the study results, experiential marketing positively affects experiential satisfaction and revisit intention directly, unlike the zoo image, which positively affects experiential satisfaction but not revisit intention. As a suggestion, Surabaya Zoo can improve visitors' image, such as improving the services provided and adding engaging experiential marketing to attract visitors' engagement again in the future.
\end{abstract}

Keywords: experiential marketing; experiential satisfaction; revisit intention; zoo; zoo image.

\section{PENDAHULUAN}

Salah satu wisata tertua dengan konsep margasatwa ialah kebun binatang. Kebun binatang sebagai tempat edukasi serta tempat melestarikan hewan dari ancaman kepunahan sehingga dijadikan contoh upaya penangkaran. Kebun binatang memiliki empat peranan penting. Pertama sebagai sarana edukasi mengenai satwa yang ada di dunia. Kedua sebagai sarana rekreasi untuk menghilangkan kejenuhan, kelelahan, tempat berkumpul dan bermain bersama keluarga maupun teman dekat. Ketiga sebagai sarana penelitian dan pengembangan untuk memerluas pemahaman serta apresiasi masyarakat. Terakhir, sebagai sarana konservasi ex-situ untuk pelestarian dan usaha perawatan satwa (Higginbottom \& Scott, 2015).

Kebun Binatang Surabaya (KBS) merupakan salah satu kebun binatang terkenal yang ada di Indonesia. KBS pernah mendapatkan predikat sebagai kebun binatang terluas dan terbesar se-Asia Tenggara. KBS didirikan pada tanggal 31 Agustus 1916 oleh H.F.K Kommer, seorang jurnalis yang hobinya mengumpulkan dan merawat berbagai jenis binatang. KBS menjadi rumah bagi 211 spesies terdiri dari 2.236 hewan Indonesia maupun dunia meliputi aves, reptil, pisces dan mamalia Fungsi KBS sebagai salah satu sumber lapangan pekerjaan, sarana konservasi hewan langka, sebagai tempat wisata margasatwa dengan harga terjangkau, sebagai tempat edukasi serta riset dan pengembangan (surabayazoo.co.id, 2018).

KBS mengalami berbagai permasalahan dalam perjalanannya seperti pengembangan kawasan, perkembangan kota, peningkatan polusi udara dan bertambahnya populasi di Surabaya (Putri et al., 2015). KBS belum dikelola secara optimal hingga keberadaannya sebagai aset pariwisata kurang mendapat respon positif dari wisatawan (Irsyad et al., 2017). Terjadinya konflik kepemilikan KBS menimbulkan masalah hukum, ketenagakerjaan, keuangan, kepengurusan dan lainnya. Berdasarkan 
Viyo Tri Taraoktavia \& Tias Andarini Indarwati. Pengaruh Experiential Marketing dan Zoo Image terhadap Revisit Intention dengan Experiential Satisfaction sebagai Variabel Intervening

observasi yang dilakukan, diketahui bahwa KBS saat ini memiliki kondisi yang tidak baik dilihat dari kondisi lingkungan dan fasilitas yang tersedia. Terdapat beberapa pengunjung membuang sampah sembarangan hingga tersebar dan mengotori seluruh area. Terdapat fasilitas yang belum bahkan tidak memadai contohnya toilet, beberapa akuarium rusak, tempat foto kurang menarik, wifi corner diletakkan di tempat yang kurang strategis karena jarang dilalui pengunjung dan tidak berada di pusat keramaian hingga sulit ditemukan. Permasalahan tersebut dapat membuat pengunjung merasa risih bahkan tidak puas dengan pengalaman yang mereka dapatkan (Irsyad et al., 2017).

Permasalahan di atas membuat pemerintah setempat menetapkan Peraturan Daerah Kota Surabaya Nomor 19 Tahun 2012 tentang Perusahaan Daerah Taman Satwa Kebun Binatang Surabaya. Namun, hal tersebut tidak menghilangkan masalah yang terjadi di Kebun Binatang Surabaya. Semakin sedikitnya hewan karena tewas dan adanya pemberitaan negatif dari media membuat image Kebun Binatang Surabaya menjadi buruk. Seperti pada 2010, matinya hewan langka yang terjadi secara terus-menerus yaitu komodo, buaya, harimau Sumatra, singa Afrika dan rusa bawean sehingga Kementrian Kehutanan sempat mencabut izin operasi. Tahun 2013 dan 2014, kasus serupa terjadi dan mengakibatkan 167 hewan mati dengan riwayat kematian yang sangat beragam (Hartiana, 2014). Kasus ini membuat media cetak pupuler di Surabaya yaitu Harian Jawa Pos dan Koran Sindo menuliskan dan menempatkannya di halaman nasional surat kabar hingga menjadi sorotan dunia (Hartiana, 2014).

Image buruk akan berdampak pada keberlangsungan KBS dilihat dari jumlah pengunjung. Wu et al. (2018), Wu et al. (2016), dan Prayag et al. (2015) menjelaskan image sebagai salah satu elemen penting dalam perusahaan agar dapat meningkatkan kepuasan dalam pengalaman wisatawan. Zoo image merupakan jumlah dari kepercayaan, ide atau kesan yang dimiliki pengunjung dari kebun binatang. Zoo image juga berpengaruh terhadap keinginan pengunjung untuk berkunjung kembali. Jika image yang didapat KBS buruk di mata pengunjung maka sulit untuk merubah image menjadi lebih baik.

Kesulitan tersebut terjadi karena pengunjung merasa tidak puas dengan pengalaman yang didapat sehingga menyebabkan ketidakinginan untuk berkunjung kembali. Sesuai dengan pendapat Indarwati \& Tiarawati (2015), Tsaur et al. (2007), Li \& Lee (2016), Lin (2019), dan Chen \& Chen (2010) satisfaction dipengaruhi oleh experiential marketing. Masalah pada KBS seperti yang telah disebutkan dapat membuat pengalaman yang didapat pengunjung menjadi tidak sesuai dengan harapan. Ketidaksesuaian harapan mengakibatkan ketidakpuasan pengunjung sehingga pengunjung tidak ingin berkunjung kembali ke Kebun Binatang Surabaya. Seperti halnya Milman \& Tasci (2017), Liu (2016), dan Wang et al. (2015) menyatakan experiential marketing sebagai faktor pendorong utama wisatawan untuk berkunjung kembali dan berpengaruh terhadap revisit intention. Experiential marketing merupakan pendekatan pemasaran yang melibatkan emosi dan perasaan konsumen dengan menciptakan pengalaman-pengalaman positif yang tidak terlupakan sehingga konsumen mengkonsumsi dan fanatik terhadap produk tertentu (Indarwati \& Tiarawati, 2015).

Revisit intention pada KBS dapat dilihat dari peningkatan jumlah pengunjung setiap tahunnya. Berdasarkan Badan Pusat Statistik Surabaya (BPS Surabaya, 2019) dan (Satvikadewi \& Kusumaningrum, 2019), jumlah pengunjung Kebun Binatang Surabaya terus mengalami peningkatan. Mulai dari 953.459 pengunjung di tahun 2014, 1.340 .883 di tahun 2015, tahun 2016 dengan 1.351.533 orang, tahun 2017 berjumlah 1.584 .726 pengunjung, tahun 2018 sebanyak 2.010 .000 orang serta tahun 2019 sebanyak 2.500 .000 orang.

Peristiwa ini tidak sejalan dengan Wu et al. (2018), Wu et al. (2016) dan Prayag et al. (2015) bahwa image baik dan pengalaman yang didapat pengunjung optimal akan berdampak pada kepuasan yang dirasakan dan memengaruhi keinginan pengunjung untuk berkunjung kembali. Peristiwa di atas juga tidak sejalan dengan penelitian Indarwati \& Tiarawati (2015), Tsaur et al.(2007), Li \& Lee (2016), Lin (2019), dan Chen \& Chen (2010) di mana experiential satisfaction akan meningkat jika experiential marketing yang diberikan positif dan sesuai bahkan melebihi harapan pengunjung sehingga memengaruhi keinginan mereka untuk berkunjung kembali di kemudian hari. 
Penelitian ini bertujuan untuk membahas pengaruh experiential marketing dan zoo image terhadap revisit intention dengan experiential satisfaction sebagai variabel intervening.

\section{KAJIAN PUSTAKA DAN PENGEMBANGAN HIPOTESIS}

\section{Experiential Marketing}

Experiential marketing menjadi filosofi manajemen pemasaran berasal dari konsep ekonomi pengalaman (Musa et al., 2015). Experiential marketing merupakan pendekatan pemasaran menggunakan emosi dan perasaan konsumen dengan cara menciptakan pengalaman positif dan tak terlupakan sehingga konsumen menjadi fanatik terhadap produk (Indarwati \& Tiarawati, 2015). Etkin dan Sela (Lin, 2019) mendefinisikan experiential marketing sebagai suatu pemasaran yang dilakukan melalui indera, emosi, tindakan, pemikiran, serta hubungan sehingga pelanggan disajikan pengalaman unik dan mengidentifikasi produk atau layanan untuk meningkatkan nilai konsumsi keseluruhan. Schmitt (2013) menyatakan terdapat empat karakteristik utama di dalamnya, yaitu pengalaman pelanggan menjadi titik fokus, konsumsi sebagai pengalaman holistik, pelanggan mengonsumsi produk menggunakan emosional, dan rasional serta metode dan alat yang elektik (pengukuran menggunakan beragam metode dan alat). Terdapat lima dimensi dalam experiential marketing yang digunakan menjadi indikator yaitu indra (sense), emosi (feel), pemikiran kognitif (think), tindakan (act), dan hubungan sosial (relate) (Schmitt, 2013).

\section{Zoo Image}

Image menjadi faktor penjelas dari teori ilmu perilaku. Citra atau image merupakan representasi mental konsumen dari perusahaan dan menekankan sifatnya yang sangat subyektif (Loureiro \& Gonzalez, 2013). Konsep image sebagai faktor penjelas dari dalam ilmu perilaku dan dianggap sebagai komponen strategi kompetitif (Wu et al., 2016). Wu et al., (2016) mendefinisikan image perusahaan sebagai kesan, kepercayaan, dan perasaan yang dimiliki individu tentang organisasi. Wu et al. (2016) mendefinisikan zoo image merupakan jumlah dari kepercayaan, ide atau kesan yang dimiliki pengunjung dari kebun binatang. Dengan kata lain, zoo image dianggap sebagai hasil dari bagaimana pengunjung merasakan kebun binatang atau visi mereka terhadap kebun binatang. Wu et al. (2018) menggunakan tiga indikator dengan obyek taman hiburan serta Wu \& Li (2017) dengan tiga indikator pada obyek situs warisan budaya. Indikator yang digunakan sebagai dasar adalah indikator dari Wu et al. (2016) disesuaikan dengan obyek penelitian.

\section{Experiential Satisfaction}

Satisfaction (kepuasan) adalah perasaan seseorang yang terjadi karena membandingkan hasil produk terhadap ekspektasi mereka. Perasaan yang muncul dapat berupa senang ataupun kecewa (Kotler dan Keller, 2008). Indarwati \& Tiarawati (2015) mendefinisikan satisfaction sebagai perbedaan dari kinerja yang dirasakan dengan harapan yang didapat. Kepuasan merupakan variabel penting dalam pengalaman. Wu et al. (2018) mendefinisikan experiential satisfaction sebagai kepuasan yang dialami dari konten layanan yang terkait dengan transaksi tertentu. Experiential satisfaction juga dapat didefinisikan sebagai kepuasan pengunjung secara keseluruhan dengan kunjungan yang mereka alami di kebun binatang (Wu et al., 2016). Pengunjung membandingkan pengalaman mereka dengan harapan mereka sebelumnya. Respon yang dihasilkan dapat berupa perasaan puas maupun tidak puas. Wu et al. (2018) menggunakan tiga indikator variabel experiential satisfaction pada taman hiburan. Wu \& Li (2017) mengunakan empat indikator. Wu et al. (2016) dengan obyek kebun binatang menggunakan tiga indikator yaitu kepuasan, perjalanan serta manfaat sehingga menjadi dasar indikator.

\section{Revisit Intention}

Konsep revisit intention diartikan sebagai niat dari pengunjung untuk revisit dengan waktu satu tahun dan kesediaan mereka untuk sering berkunjung ke tujuan (Wu et al., 2018). Wang et al. (2015) menggambarkan revisit intention sebagai ekspresi dari loyalitas dengan pengunjung berkemungkinan untuk berkunjung kembali ke sebuah destinasi. Wu et al. (2016) menguji niat berkunjung kembali, hubungan kualitas dan kepuasan antara pengunjung ke kebun binatang dengan hasil menemukan 
Viyo Tri Taraoktavia \& Tias Andarini Indarwati. Pengaruh Experiential Marketing dan Zoo Image terhadap Revisit Intention dengan Experiential Satisfaction sebagai Variabel Intervening

bahwa kualitas pengiriman, manfaat rekreasi, dan kepuasan keseluruhan mendasari niat pengunjung untuk berkunjung kembali dan merekomendasikannya kepada pengunjung lain. Ia menggunakan lima indikator pada variabel revisit intention. Wu et al. (2018) menggunakan tiga indikator pada obyek taman hiburan. Indikator dari Wu et al. (2016) menjadi dasar indikator yang disesuaikan dengan obyek penelitian.

\section{Hubungan antar Variabel}

Experiential marketing diterapkan pada suatu bisnis dapat meningkatkan kepuasan dari pengalaman pelanggan. Sense, feel, think, act, dan relate merupakan dimensi dari experiential marketing yang digunakan untuk meningkatkan kepuasan (Schmitt, 2013). Indarwati \& Tiarawati (2015) menjelaskan kepuasan pelanggan dan loyalitas pelanggan J.Co Donuts \& Caffe dipengaruhi oleh experiential marketing yang dilakukan perusahaan. Tsaur et al. (2007) mendapatkan hasil di mana experiential marketing yang dilakukan pada Kebun Binatang Taipei berpengaruh positif terhadap emosi dan memengaruhi satisfaction. Li \& Lee (2016) menjelaskan bahwa experience pada Resort hotel industri menghasilkan efek langsung dengan kepuasan pelanggan. Begitu pula pada sektor ecotourism Taiwan yang diteliti oleh Lin (2019) dan tourism factories oleh Chen \& Chen (2010) menghasilkan hubungan positif antar keduanya.

\section{H1: Experiential marketing berpengaruh positif terhadap experiential satisfaction.}

Wu \& Li (2017) dan Wu et al. (2016) menerangkan bahwa experiential quality berpengaruh positif terhadap experiential satisfaction melewati image. Agar dapat meningkatkan loyalitas pelanggan, image menjadi elemen yang harus dimiliki oleh semua perusahaan. Image menjadi faktor kritikal dalam memengaruhi kepuasan. Pernyataan ini sejalan dengan Loureiro \& Gonzalez (2013) di mana image merupakan anteseden langsung dari perceived quality, satisfaction, trust dan loyalty pada rural tourism. Menurut Prayag et al. (2013) hubungan image dan behavioral loyalty dimediasi oleh satisfaction. Jin, et al. (2013); Lee et al., (2010) juga Prayag et al. (2015) juga menyatakan image memiliki pengaruh terhadap satisfaction.

\section{$\mathrm{H} 2$ : Zoo image berpengaruh positif terhadap experiential satisfaction.}

Pengunjung merasa puas jika pengalaman yang didapatkan melebihi harapan mereka. Kepuasan dapat membuat pengunjung ingin berkunjung dikemudian hari. Saikim et al. (2019) berpendapat experience berpengaruh terhadap loyalitas pengunjung dibuktikan dengan keinginan pengunjung untuk mengunjungi Sabah, Malaysia. Liu (2016) dan Milman \& Tasci (2017) menyebutkan dimensi experience marketing dapat memengaruhi keinginan wisatawan untuk berkunjung kembali. Wang et al. (2012) meneliti dengan obyek water park mendapati experience sebagai faktor pendorong utama wisatawan untuk berkunjung kembali. Meskipun sudah banyak penelitian tentang pengaruh experiential marketing terhadap satisfaction, namun masih jarang penelitian tentang experiential marketing dengan menggunakan dimensi dari (Schmitt, 2013) yaitu sense, feel, think, act dan relate terhadap kepuasan yang terfokus pada pengalaman pengunjung.

\section{H3: Experiential marketing berpengaruh positif terhadap revisit intention.}

Wu et al. (2016) berpendapat bahwa image yang dilakukan pada Kebun Binatang Beijing memegang peranan penting dalam menaikkan keinginan pengunjung untuk berkunjung kembali. Sejalan dengan Wu et al. (2018), image merupakan anteseden dari revisit intention. Hasan et al.(2019) dan Wu \& Li (2017) menghasilkan hal serupa di mana image menjadi anteseden dan berpengaruh secara positif terhadap revisit intention. Menurut $\mathrm{Wu}$ et al. (2017) zoo image, visitors' affective commitment dan visitors' experiential satisfaction berpengaruh positif pada visitors' revisit intentions.

H4: Zoo image berpengaruh positif terhadap revisit intention Kebun Binatang Surabaya.

Jika wisatawan merasa puas terhadap obyek wisata yang mereka kunjungi maka mereka pasti akan kembali lagi untuk merasakan kepuasan yang pernah mereka dapatkan atau bahkan berharap lebih. 
Assaker et al. (2011) berpendapat bahwa satisfaction berpengaruh langsung terhadap jangka pendek namun tidak pada jangka panjang kecuali kepuasan terus dikembangkan oleh pemasar. Chen \& Chen (2010) berpendapat bahwa satisfaction berpengaruh secara signifikan dan positif terhadap behavioral intention di mana revisit menjadi bagian dari behavioral intention. Penelitian dengan hasil serupa dilakukan Wang et al. (2015) ada pengaruh positif dan signifikan antara satisfaction dan revisit intention. Namun berbeda dengan Hajar et al. (2015) satisfaction tidak memengaruhi revisit intention. Hal ini dikarenakan hiker's revisit intention lebih ditentukan oleh fitur dari assessment of pull factor. Dalam beberapa penelitian sebelumnya juga belum ditemukan terkait pengaruh experiential satisfaction terhadap revisit intention dalam industri pariwisata zoology.

H5: Experiential satisfaction berpengaruh positif terhadap revisit intention Kebun Binatang Surabaya.

Dari hipotesis di atas dapat digambarkan model penelitian pada Gambar 1.

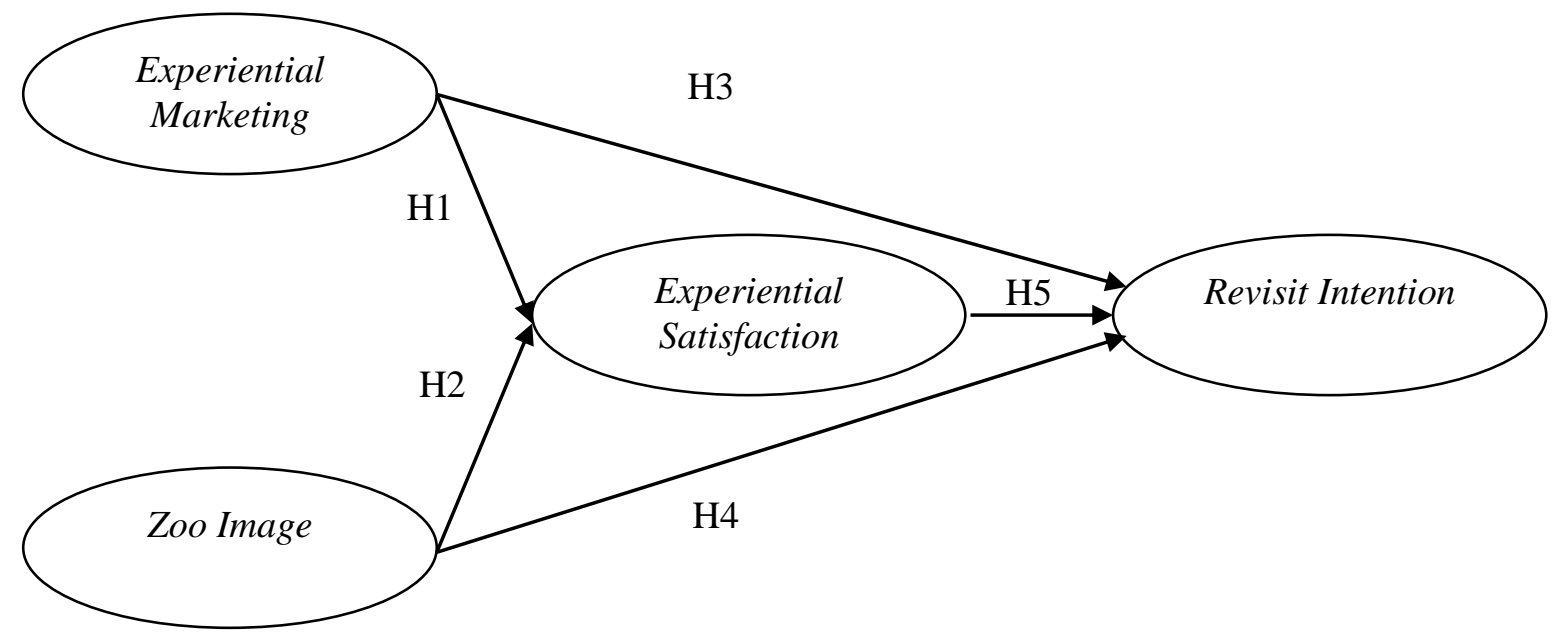

Sumber: Tsaur et al. (2007) dan Wu et al. (2016), data diolah

\section{Gambar 1. MODEL PENELITIAN}

\section{METODE PENELITIAN}

Penelitian ini untuk mengetahui apakah terdapat pengaruh experiential marketing dan zoo image terhadap revisit intention dengan experiential satisfaction menjadi variabel intervening. Jenis penelitian yaitu konklusif bertujuan untuk mengetahui suatu hipotesis dan suatu hubungan. Obyek penelitian adalah Kebun Binatang Surabaya yang terletak di Jalan Setail nomor 1 Darmo Kecamatan Wonokromo Kota Surabaya, Jawa Timur. Data yang digunakan adalah data primer dan data sekunder. Data primer didapat dari hasil angket dan disebarkan secara online yaitu dengan memberikan pesan langsung atau direct massage pada pengikut akun sosial media KBS. Setelah itu menanyakan terkait karakteristik responden yang dicari. Jika pengikut akun sosial media KBS sesuai dengan karakteristik yang dicari selanjutnya meminta kesediaan mereka mengisi angket penelitian yang diberikan berupa link angket. Angket menggunakan skala likert poin 1 yaitu sangat tidak setuju hingga poin 5 yaitu sangat setuju (Malhotra \& Birks, 2007). Data sekunder dalam penelitian berupa buku, jurnal, maupun artikel yang berkaitan dengan experiential marketing, zoo image, experiential satisfaction, dan revisit intention.

Populasi pada penelititan bersifat infinite atau tidak terbatas yaitu semua wisatawan yang mengunjungi Kebun Binatang Surabaya. Sampel menggunakan teknik nonprobability sampling yaitu purposive sampling untuk memilih berdasarkan karakteristik yang telah ditentukan. Jumlah sampel sebesar 200 responden dengan tingkat kesalahan 5\% (untuk mengantisipasi kesalahan yang akan terjadi) sehingga diambil 210 responden (Malhotra \& Birks, 2007). Karakteristik sampel adalah 
Viyo Tri Taraoktavia \& Tias Andarini Indarwati. Pengaruh Experiential Marketing dan Zoo Image terhadap Revisit Intention dengan Experiential Satisfaction sebagai Variabel Intervening

sebagai berikut: (1) Responden telah berkunjung minimal satu kali sebelum berlakunya WFH (Work From Home) karena Covid-19; (2) Responden berusia 18-35 tahun karena usia tersebut dianggap cukup dewasa untuk mengerti pertanyaan yang diajukan, dapat membuat keputusan yang dapat dipertanggungjawabkan, masuk dalam kategori generasi milenial yang mampu berinovasi, memiliki pola pikir terbuka, kritis, dan menguasai teknologi (W et al., 2019). (3) Responden merupakan lakilaki dan perempuan. (4) Responden berdomisili di Jawa Timur.

Uji validitas dan reliabilitas menggunakan program IBM SPSS 25. Analisis menggunakan teknik analisis jalur (Path analysis) dengan AMOS versi 23.

\section{HASIL DAN PEMBAHASAN}

\section{Karakteristik Responden}

Tabel 1. menunjukkan mayoritas responden berusia 18-25 tahun, berjenis kelamin perempuan dengan status belum menikah, berpendidikan terakhir SMA dengan pekerjaan sebagai mahasiswa dan memiliki pengeluaran per bulan rata-rata kurang dari Rp1.000.000,-.

Tabel 1.

KARAKTERISTIK RESPONDEN

\begin{tabular}{|c|c|c|c|}
\hline \multicolumn{2}{|c|}{ Keterangan } & \multirow{2}{*}{$\begin{array}{l}\text { Jumlah } \\
45\end{array}$} & \multirow{2}{*}{$\begin{array}{l}\text { Presentase }(\%) \\
22.5 \%\end{array}$} \\
\hline Jenis Kelamin & Laki-laki & & \\
\hline & Perempuan & 155 & $77.5 \%$ \\
\hline \multirow[t]{2}{*}{ Usia } & $18-25$ tahun & 158 & $79 \%$ \\
\hline & 26-35 tahun & 42 & $21.0 \%$ \\
\hline \multirow[t]{2}{*}{ Status } & Belum Menikan & 166 & $83 \%$ \\
\hline & Menikah & 34 & $17 \%$ \\
\hline \multirow[t]{4}{*}{ Pendidikan terakhir } & SMA & 130 & $65 \%$ \\
\hline & Diploma & 16 & $8 \%$ \\
\hline & Sarjana Strata I & 52 & $26 \%$ \\
\hline & Sarjana Strata II & 2 & $1 \%$ \\
\hline \multirow[t]{6}{*}{ Pekerjaan } & Mahasiswa & 134 & $67.0 \%$ \\
\hline & Pegawai Negeri Sipil & 5 & $2.5 \%$ \\
\hline & Ibu Rumah Tangga & 7 & $3.5 \%$ \\
\hline & Karyawan Swasta & 32 & $16.0 \%$ \\
\hline & Wiraswasta & 6 & $3.0 \%$ \\
\hline & Lainnya & 16 & $8.0 \%$ \\
\hline \multirow[t]{6}{*}{ Pengeluaran per bulan } & $<$ Rp1.000.000 & 116 & $58.0 \%$ \\
\hline & Rp1.000.000 - Rp2.999.999 & 49 & $24.5 \%$ \\
\hline & Rp3.000.000 - Rp4.999.999 & 24 & $12.0 \%$ \\
\hline & Rp5.000.000 - Rp6.999.999 & 6 & $3.0 \%$ \\
\hline & Rp7.000.000 - Rp8.999.999 & 2 & $1.0 \%$ \\
\hline & $>$ Rp9.000.000 & 3 & $1.5 \%$ \\
\hline Total & & 200 & 200 \\
\hline
\end{tabular}

Sumber: Output SPSS (2021, data diolah)

Pengujian validitas menggunakan product moment pearson correlation. Jika r-hitung > r-tabel yaitu 0,361 serta hasil bernilai positif maka data dikatakan valid. Namun data tidak valid jika nilai r-hitung < nilai r-tabel. Pengujian reliabilitas menggunakan nilai cronbach's alpha. Nilai cronbach's alpha > 0,60 berarti data yang digunakan menjadi reliabel. berlaku untuk sebaliknya, jika nilai cronbach's alpha > 0,60 maka data tidak reliabel. Hasil uji validitas dan reliabilitas, semua item pada kuesioner terbukti valid dan reliable. Hasil uji validitas dan reliabilitas di tabel 2. 
Tabel 2.

HASIL UJI VALIDITAS DAN RELIABILITAS

\begin{tabular}{|c|c|c|}
\hline Variabel dan Butir-butir Pernyataan & $\begin{array}{c}\text { Correlated item } \\
\text { total }\end{array}$ & $\begin{array}{l}\text { Cronbach's } \\
\text { alpha }\end{array}$ \\
\hline Experiential Marketing (X1) & & \multirow{15}{*}{0,911} \\
\hline $\begin{array}{l}\text { Suara-suara unik yang dikeluarkan binatang menyenangkan untuk } \\
\text { didengar }\end{array}$ & 0.475 & \\
\hline $\begin{array}{l}\text { Kebun Binatang Surabaya memiliki koleksi binatang yang sangat } \\
\text { menarik untuk dilihat }\end{array}$ & 0.790 & \\
\hline Lingkungan Kebun Binatang Surabaya asri & 0.709 & \\
\hline $\begin{array}{l}\text { Saya senang saat berinteraksi dengan binatang di Kebun Binatang } \\
\text { Surabaya }\end{array}$ & 0.712 & \\
\hline Saya menikmati suasana Kebun Binatang Surabaya & 0.780 & \\
\hline $\begin{array}{l}\text { Kebun Binatang Surabaya menjaga keamanan pengunjung dari } \\
\text { satwa yang ada }\end{array}$ & 0.667 & \\
\hline $\begin{array}{l}\text { Saya menikmati waktu yang berkualitas bersama keluarga atau } \\
\text { teman saat berada di Kebun Binatang Surabaya }\end{array}$ & 0.590 & \\
\hline $\begin{array}{l}\text { Kebun Binatang Surabaya memiliki program tur edukasi yang } \\
\text { membuat saya tertarik }\end{array}$ & 0.733 & \\
\hline $\begin{array}{l}\text { Kebun Binatang Surabaya memiliki papan informasi yang } \\
\text { mendorong keingintahuan saya }\end{array}$ & 0.776 & \\
\hline $\begin{array}{l}\text { Berada di Kebun Binatang Surabaya membuat saya memikirkan } \\
\text { peran binatang dalam kehidupan }\end{array}$ & 0.859 & \\
\hline $\begin{array}{l}\text { Saya menceritakan pengalaman saya saat berada di Kebun } \\
\text { Binatang Surabaya kepada orang lain }\end{array}$ & 0.585 & \\
\hline $\begin{array}{l}\text { Saya mengambil foto atau gambar dalam Kebun Binatang } \\
\text { Surabaya sebagai kenangan }\end{array}$ & 0.591 & \\
\hline $\begin{array}{l}\text { Saya membeli souvenir yang berhubungan dengan Kebun } \\
\text { Binatang Surabaya }\end{array}$ & 0.584 & \\
\hline Kebun Binatang Surabaya membuat saya peduli lingkungan & 0.808 & \\
\hline \multicolumn{3}{|l|}{ Zoo Image (X2) } \\
\hline Kebun Binatang Surabaya menyediakan layanan yang baik & 0.887 & \multirow{3}{*}{0,852} \\
\hline Kebun Binatang Surabaya memiliki area yang luas & 0.842 & \\
\hline Kebun Binatang Surabaya memiliki suasana yang menyenangkan & 0.907 & \\
\hline \multicolumn{3}{|l|}{ Experiential Satisfaction (Z) } \\
\hline Berkunjung ke Kebun Binatang Surabaya melebihi harapan saya & 0.904 & \multirow{3}{*}{0,894} \\
\hline Saya sangat suka berkunjung ke Kebun Binatang Surabaya & 0.945 & \\
\hline $\begin{array}{l}\text { Saya mendapatkan manfaat saat berada di Kebun Binatang } \\
\text { Surabaya }\end{array}$ & 0.890 & \\
\hline \multicolumn{3}{|l|}{ Revisit Intention $(Y)$} \\
\hline $\begin{array}{l}\text { Saya ingin berkunjung kembali ke Kebun Binatang Surabaya } \\
\text { dalam waktu dekat }\end{array}$ & 0.835 & \multirow{5}{*}{0,849} \\
\hline $\begin{array}{l}\text { Jika saya harus membuat keputusan ulang, saya akan memilih } \\
\text { untuk berkunjung Kebun Binatang Surabaya kembali }\end{array}$ & 0.707 & \\
\hline $\begin{array}{l}\text { Saya akan berkunjung kembali ke Kebun Binatang Surabaya di } \\
\text { masa depan }\end{array}$ & 0.860 & \\
\hline Saya akan sering berkunjung ke Kebun Binatang Surabaya & 0.844 & \\
\hline $\begin{array}{l}\text { Kebun Binatang Surabaya menjadi destinasi pertama yang saya } \\
\text { kunjungi daripada destinasi lainnya }\end{array}$ & 0.747 & \\
\hline
\end{tabular}

Sumber: Output SPSS (2021, data diolah)

Data dianalisis menggunakan path analisis. Tahapan yang digunakan adalah (1) melakukan uji asumsi dengan cara menguji normalitas, linieritas, outlier serta multikolinearitas, (2) menguji kelayakan pada model penelitian, (3) merancang model (dengan jalur), (4) mengkonversi diagram jalur kedalam persamaan, (5) menguji square multiple correlation, (6) menguji hipotesis, (7) menginterpretasi hasil analisis, (8) menguji mediasi, dan (9) dan menguji sobel test. Hasil uji normalitas menyatakan data 
Viyo Tri Taraoktavia \& Tias Andarini Indarwati. Pengaruh Experiential Marketing dan Zoo Image terhadap Revisit Intention dengan Experiential Satisfaction sebagai Variabel Intervening

berdistribusi normal karena nilai critical ratio (CR) di antara -2,58 dan 2,58. Model memenuhi asumsi uji linieritas dikarenakan nilai kurang dari 0,05. Pada uji outlier, data memenuhi asumsi uji outlier karena nilai mahalanobis distance squared tidak melebihi nilai chi square $(18,467)$ atau $\mathrm{p} 2<0,05$. Uji multikolinearitas diketahui determinant of sample covariance matrix sebesar 584,250>0 dengan condition number 15,632. Uji kelayakan model didapat koefisien determinasi sebesar 85,8\%. Ini membuktikan bahwa kontribusi model yang diteliti sebesar 85,85\% dan 14,2\% lainnya dijelaskan oleh variabel lain.

\section{Hasil Path Analysis}

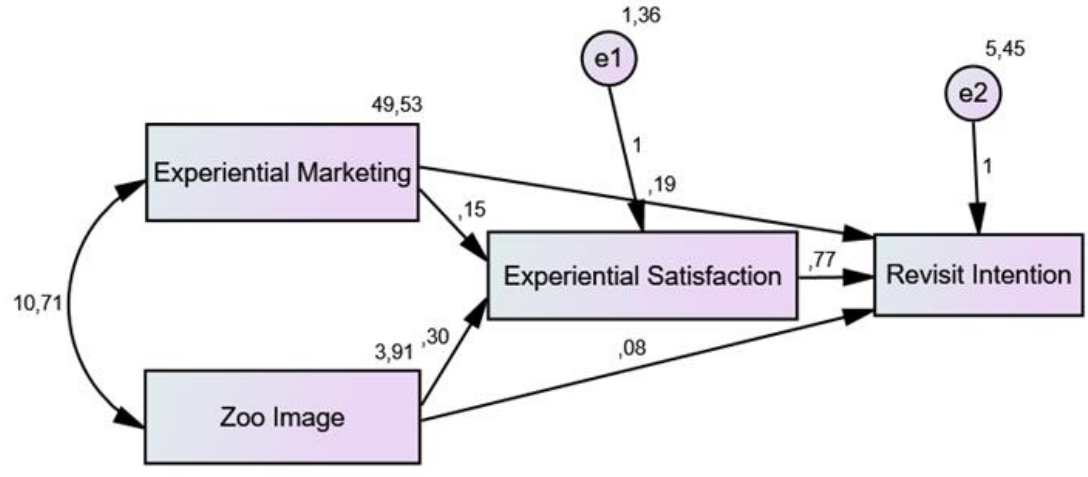

Sumber: Output Amos 23 (2021)

Gambar 2. HASIL UJI PATH ANALYSIS

Gambar 2 menunjukkan hasil analisis path yang dituliskan menjadi bentuk persamaan (1) dan (2).

$\mathrm{Z}=0,15 \mathrm{X} 1+0,030 \mathrm{X} 2+0,348$

$\mathrm{Y}=0,19 \mathrm{X} 1+0,08 \mathrm{X} 2+0,77 \mathrm{Z}+0,348$

\section{Hasil Uji Hipotesis}

Hasil pengujian hipotesis 1 sampai 5 secara menyeluruh ditunjukkan pada tabel 3.

Tabel 3.

\section{HASIL UJI HIPOTESIS}

\begin{tabular}{lllccl}
\hline Hipotesis & \multicolumn{1}{c}{ Variabel } & Estimate & S.E. & C.R. & \multicolumn{1}{c}{ P } \\
\hline H1 & Korelasi experiential marketing ke experiential satisfaction & 0,154 & 0,019 & 8,154 & 000 \\
H2 & Korelasi zoo image ke experiential satisfaction & 0,302 & 0,067 & 4,487 & 000 \\
H3 & Korelasi experiential marketing ke revisit intention & 0,188 & 0,044 & 4,248 & 000 \\
H4 & Korelasi zoo image ke revisit intention & 0,080 & 0,142 & 0,564 & 0,572 \\
H5 & Korelasi experiential satisfaction ke revisit intention & 0,768 & 0,147 & 5,241 & 000 \\
\hline
\end{tabular}

Sumber: Data diolah (2021)

Hipotesis diterima atau tidak dapat diamati dari nilai signifikansi $(\alpha)$ serta $p$-value. Hipotesis diterima jika nilai $p$-value $<0,05$. Selain itu hasil pengujian ini dapat menunjukkan apakah kedua variabel memiliki pengaruh dan signifikan atau tidak. Berdasarkan tabel 3 nilai CR 8,154>2,00 dan nilai signifikansi 0,000 artinya kurang dari 0,05 sehingga $\mathrm{H} 1$ diterima. Begitu juga $\mathrm{H} 2$ diterima, H3 diterima dan H5 diterima. Namun H4 ditolak karena nilai CR 0,564 <2,00 dan nilai signifikansi sebesar 0,572 >0,05 sehingga zoo image berpengaruh positif terhadap revisit intention namun tidak signifikan.

Tahap selanjutnya dilakukan uji direct, uji indirect dan total effect pada path analysis. Nilai uji pengaruh langsung antara variabel experiential marketing dengan experiential satisfaction sebesar 
0,551. Pengaruh langsung variabel zoo image terhadap experiential satisfaction sebesar 0,303. Pengaruh experiential marketing terhadap revisit intention sebesar 0,362. Pengaruh langsung zoo image terhadap revisit intention sebesar 0,043. Pengaruh langsung variabel experiential satisfaction terhadap revisit intention sebesar 0,415. Pengaruh tidak langsung antara variabel experiential marketing terhadap revisit intention sebesar 0,229. Pengaruh tidak langsung variabel zoo image terhadap revisit intention sebesar 0,126 . Besaran pengaruh total pada penelitian diperoleh dari hasil penjumlahan antara besaran pengaruh langsung dan pengaruh tidak langsung. Pengaruh total dari variabel experiential marketing terhadap experiential satisfaction adalah 0,551. Pengaruh total dari variabel zoo image terhadap experiential satisfaction adalah 0,303. Pengaruh total dari variabel experiential marketing terhadap revisit intention adalah 0,591. Pengaruh total dari variabel zoo image terhadap revisit intention adalah 0,169 . Terakhir pengaruh total dari variabel experiential satisfaction terhadap revisit intention adalah 0,415 .

Uji selanjutnya adalah uji mediasi. Hasil uji mediasi berupa variabel experiential marketing berpengaruh signifikan secara langsung dan tidak langsung terhadap variabel revisit intention. Melalui variabel mediasi experiential satisfaction maupun tidak melalui variabel experiential satisfaction. Karena itu jalur variabel experiential marketing menunjukkan mediasi terbukti secara parsial (partially mediated). Variabel zoo image memiliki pengaruh langsung terhadap revisit intention. Namun tidak signikan. Pengaruh ini menjadi signifikan ketika melibatkan mediasi experiential satisfaction. Oleh sebab itu mediasi terbukti secara penuh (fully mediated).

Hasil sobel test yang dilakukan diketahui nilai signifikansi experiential marketing sebesar 0,00001127 $(\mathrm{p}<0,05)$. Sehingga uji sobel diterima. Maka variabel experiential marketing bepengaruh signifikan terhadap revisit intention dengan experiential satisfaction sebagai variabel mediasi. Sedangkan nilai signifikansi zoo image sebesar $0,00064291(\mathrm{p}<0,05)$. Uji sobel diterima sehingga variabel zoo image memiliki pengaruh signifikan terhadap revisit intention dengan experiential satisfaction sebagai variabel mediasi.

\section{Pengaruh Experiential Marketing terhadap Experiential Satisfaction}

Pemasar menggunakan pendekatan experiential marketing untuk menciptakan pengalaman positif dan tak terlupakan yang melibatkan emosi dan perasaan konsumen (Indarwati \& Tiarawati, 2015). Dengan memeroleh pengalaman positif yang menyenangkan membuat pengunjung dapat merasakan experiential satisfaction. Experiential satisfaction diartikan sebagai kepuasan pengunjung secara keseluruhan dengan kunjungan yang mereka alami di kebun binatang. Dari uji hipotesis terlihat adanya pengaruh secara positif antara experiential marketing dan experiential satisfaction pada Kebun Binatang Surabaya. Hasil ini sesuai dengan Indarwati \& Tiarawati (2015) yaitu adanya pengaruh experiential marketing terhadap kepuasan pelanggan J.Co Donuts \& Caffe, Tsaur et al. (2007) pada obyek kebun binatang, Li \& Lee (2016) pada resort hotel, Lin (2019) pada sector ecotourism dan Yeh, Chen, \& Chen (2019) pada sektor tourism factories.

Experiential marketing yang ditawarkan Kebun Binatang Surabaya membuat pengunjung merasa puas dengan pengalaman yang didapat. Sesuai hasil deskriptif responden, experiential marketing yang mendominasi adalah disajikannya suara unik dari hewan langka yang hanya bisa didengarkan di kebun binatang surabaya. pengunjung juga menikmati waktu yang dapat dihabiskan bersama keluarga atau teman mereka seraya menikmati liburan dengan lingkungan yang damai. Adanya papan informasi dalam KBS menjadikan pengunjung yang belum mengetahui informasi menjadi tahu dan dapat menambah pengetahuan mereka. Adanya tempat foto yang kekinian membuat pengunjung khususnya generasi muda aktif akan sosial media mengabadikan momen mereka dengan mengambil foto atau gambar bahkan menjadikan foto mereka sebagai informasi kepada orang lain lewat sosial media. Berkunjung ke KBS dapat membuat mereka menjadi lebih peduli akan lingkungan sekitar khususnya generasi muda yang memiliki peran penting dalam membangun negara. Dengan berbagai experiential marketing yang didapat pengunjung membuat mereka senang dan puas karena telah berkunjung dan sepadan dengan apa yang mereka keluarkan. Hal ini menjadi penyebab kenaikan jumlah Pengunjung Kebun Binatang Surabaya. 
Viyo Tri Taraoktavia \& Tias Andarini Indarwati. Pengaruh Experiential Marketing dan Zoo Image terhadap Revisit Intention dengan Experiential Satisfaction sebagai Variabel Intervening

\section{Pengaruh Zoo Image terhadap Experiential Satisfaction}

Loureiro \& Gonzalez (2013) mendefinisikan konsep image sebagai representasi mental konsumen dari perusahaan dan menekankan sifatnya yang sangat subyektif. Zoo image dianggap sebagai hasil dari bagaimana pengunjung merasakan kebun binatang atau visi mereka terhadap kebun binatang. Kotler dan Keller (2009) menjelaskan kepuasan sebagai munculnya perasaan seseorang karena membandingkan hasil produk dengan ekspektasinya. Perasaan itu dapat berupa senang ataupun kecewa. Experiential satisfaction dalam penelitian ini diartikan sebagai keseluruhan kepuasan dari pengunjung dengan kunjungan yang dialami di kebun binatang. Dilihat dari hasil uji di atas, diketahui zoo image memiliki nilai c.r lebih besar dan p-value lebih kecil sehingga zoo image berpengaruh signifikan dan positif terhadap experiential satisfaction. Terlihat pada uji direct dan indirect bahwa zoo image memiliki pengaruh langsung terhadap experiential marketing. Hasil ini didukung oleh penelitian Wu \& Li (2017) dan Wu et al. (2016), Loureiro \& Gonzalez (2013) menjelaskan pengaruh image sebagai anteseden langsung dari satisfaction, Prayag (2013), Jin et al. (2013), Lee et al. (2010), Prayag et al. (2015) yang membuktikan image memiliki pengaruh terhadap satisfaction.

Zoo image memengaruhi keinginan seseorang untuk mengunjungi kebun binatang. Zoo image menjadi faktor kritikal dalam memengaruhi kepuasan. Jika image yang tersebar positif dapat membuat seseorang untuk mengunjungi dan melihat langsung apakah image tersebut benar kenyataannya. Dengan membuktikan hal tersebut pengunjung merasakan kepuasan dari pengalaman yang didapat sama dengan image yang diharapkan atau image yang tersebar ataupun lebih besar. Sebelumnya KBS memiliki image yang buruk dalam benak pengunjung. Namun dari hasil statistik deskriptif variabel zoo image pada penelitian, yang melekat pada pengunjung terhadap Kebun Binatang Surabaya adalah bahwa kebun binatang memiliki area yang luas dan memiliki banyak manfaat jika berada di kebun binatang. Melekatnya image KBS di benak pengunjung membuat mereka ingin merasakan seberapa luas kebun binatang ini. Setelah merasakan luasnya area KBS dan mendapatkan banyak manfaat, pengunjung merasakan kepuasan karena yang mereka dapat sama dengan hasil yang mereka harapkan. Dilihat dari hasil karakteristik responden di mana responden memiliki pengeluaran rata-rata di bawah Rp1.000.000 dengan pekerjaan paling banyak yaitu mahasiswa dan berusia 18-25 tahun. Karena hal tersebut Kebun Binatang Surabaya dapat dinyatakan menjadi salah satu tempat wisata margasatwa termurah yang memiliki banyak manfaat. Dengan pembuktian yang dilakukan pengunjung membuat image buruk KBS tergeser dan menjadi lebih baik sehingga mengakibatkan kepuasan yang diterima pengunjung menjadi tinggi. Hal ini dapat dilihat dari jumlah pengunjung yang mengalami kenaikan. Sehingga zoo image berpengaruh terhadap experiential satisfaction.

\section{Pengaruh Experiential Marketing terhadap Revisit Intention}

Lin (2019) mendefinisikan experiential marketing sebagai pemasaran yang dilakukan melalui indera, emosi, tindakan, pemikiran, dan hubungan. Pelanggan disajikan pengalaman unik untuk meningkatkan nilai konsumsi keseluruhan. Wu et al. (2018) mendefinisikan revisit intention menjadi niat pengunjung untuk berkunjung kembali dalam waktu tertentu dan mereka bersedia untuk sering berkunjung ke suatu tujuan. Zoo image terbukti berpengaruh signifikan dan positif terhadap revisit intention. Experiential marketing berpengaruh secara langsung terhadap revisit intention dilihat dari hasil uji direct lebih besar dari hasil uji indirect. Hasil penelitian didukung oleh Hanisdah et al. (2019) dengan hasil experience berpengaruh terhadap loyalitas yang dibuktikan dengan keinginan pengunjung untuk mengunjungi Sabah, Malaysia. Liu (2016) serta Milman \& Tasci (2017) dengan hasil experiential marketing dapat memengaruhi keinginan wisatawan untuk berkunjung kembali. Terakhir penelitian dari Wang et al. (2012) pada obyek waterpark di mana experience sebagai faktor pendorong utama untuk berkunjung kembali.

Hasil penelitian ini, experiential marketing berpengaruh terhadap revisit intention. Artinya pengunjung mendapatkan pengalaman-pengalaman menarik dan tak terlupakan selama di Kebun Binatang Surabaya sehingga membuat mereka ingin berkunjung kembali untuk merasakan pengalaman itu terulang kembali. Seperti pengalaman yang didapat melalui pengindraan yaitu saat mengetahui suara unik yang dikeluarkan para binatang, pengalaman melalui perasaan seperti adanya layanan untuk berinteraksi bersama binatang secara dekat, adanya papan informasi dari binatang yang mereka lihat sehingga dapat menambah pengetahuan, habitat para binatang yang menarik untuk 
dilihat serta spot-spot foto untuk dijadikan sebagai kenang-kenangan. Hal-hal tersebut membuat pengunjung ingin berkunjung kembali untuk merasakan pengalaman mereka yang tak terlupakan. Terbukti dari hasil statistik variabel revisit intention dengan hasil pengunjung akan mengunjungi lagi di masa yang akan datang.

\section{Pengaruh Zoo Image terhadap Revisit Intention}

Image sebagai faktor penjelas dalam teori ilmu perilaku dan dianggap sebagai komponen strategi kompetitif. Zoo image dapat diartikan sebagai suatu komponen strategi kompetitif untuk kebun binatang. Image dapat memegang peranan penting dalam menaikkan keinginan pengunjung untuk berkunjung kembali. Hasil penelitian menunjukkan pengaruh positif variabel zoo image terhadap revisit intention namun tidak signifikan secara langsung. Artinya hipetosis ditolak. Hasil ini tidak mendukung dari penelitian sebelumnya yang dilakukan oleh Wu et al. (2018), Hasan et al. (2019), Wu \& Li (2017) serta Wu et al. (2017) dengan hasil zoo image positif memengaruhi revisit intention.

Meskipun image KBS menjadi lebih baik, hal ini tidak secara otomatis membuat pengunjung ingin berkunjung kembali. Berdasarkan jawaban responden mengenai variabel zoo image, butir "Kebun Binatang Surabaya menyediakan layanan yang baik" mendapat nilai terendah dari butir lainnya. Pada variabel revisit intention item terendah dimiliki oleh item Y5 dengan pernyataan "Kebun Binatang Surabaya menjadi destinasi pertama yang saya kunjungi daripada destinasi lainnya". Hal ini membuktikan bahwa layanan yang disediakan pihak KBS masih kurang baik dan tidak bersaing dengan layanan yang diberikan oleh destinasi wisata lain. Ketika menyadari hal tersebut responden tidak menjadikan KBS sebagai pilihan destinasi pertama yang ingin dikunjungi dan memilih destinasi yang lain dengan layanan yang lebih baik daripada Kebun Binatang Surabaya. Untuk itu pihak KBS perlu memberikan layanan yang memuaskan sesuai dengan harapan dari pengunjung agar KBS menjadi destinasi pertama yang ingin dikunjungi.

\section{Pengaruh Experiential Satisfaction terhadap Revisit Intention}

Experiential Satisfaction diartikan sebagai kepuasan pengunjung dengan kunjungan yang dialami di kebun binatang. Pengunjung membandingkan pengalaman yang mereka dapatkan dengan harapan mereka sebelumnya. Respon yang didapat dapat berupa puas atau tidak puas. Wu et al. (2016) menemukan bahwa niat untuk berkunjung kembali didasarkan pada kepuasan keseluruhan. Hasil penelitian menjelaskan experiential satisfaction berpengaruh secara signifikan dan positif terhadap revisit intention. Hasil ini didukung oleh beberapa peneliti. Chen \& Chen (2010) hasilnya yaitu ada pengaruh positif dan signifikan antara satisfaction dengan behavioral intentenion di mana revisit menjadi bagian dari behavioural intention. Assaker et al. (2011) berpendapat bahwa revisit intention jangka pendek memengaruhi satisfaction secara langsung. Wang et al. (2015) terdapat pengaruh positif dan signifikan antara satisfaction dan revisit intention.

Experiential satisfaction berpengaruh terhadap revisit intention. Sesuai jawaban responden, pengunjung merasa puas dengan berkunjung ke Kebun Binatang Surabaya di mana mereka mendapatkan banyak manfaat selama berada disana. Salah satu manfaat yang didapat yaitu pengunjung dapat berlibur ke destinasi wisata alam dengan budget yang murah, mendapat berbagai pengetahuan tentang binatang yang tidak terpikirkan sebelumnya dengan melihat papan informasi yang diberikan. Pengunjung juga bisa menikmati waktu liburan dengan keluarga maupun teman sehingga dapat memererat ikatan kekeluargaan. Lingkungan yang asri juga membuat pengunjung menikmati dan peduli dengan lingkungan sekitar. Area yang luas dapat membuat kondisi pengunjung menjadi lebih sehat. Dengan kepuasan yang dirasakan pengunjung dapat menjadikan pengunjung untuk berkunjung kembali ke Kebun Binatang Surabaya.

\section{KESIMPULAN}

Dari hasil analisis data, terdapat pengaruh positif experiential marketing terhadap experiential satisfaction, terdapat pengaruh positif experiential marketing terhadap revisit intention, terdapat pengaruh positif experiential satisfaction terhadap revisit intention serta terdapat pengaruh positif zoo 
Viyo Tri Taraoktavia \& Tias Andarini Indarwati. Pengaruh Experiential Marketing dan Zoo Image terhadap Revisit Intention dengan Experiential Satisfaction sebagai Variabel Intervening

image terhadap experiential satisfaction. Namun zoo image berpengaruh positif terhadap revisit intention tetapi tidak signifikan. Hal ini dibuktikan dengan adanya responden tidak menjadikan wisata KBS menjadi destinasi pertama mereka yang ingin mereka kunjungi kembali daripada destinasi wisata lainnya.

Saran yang dapat diberikan untuk keberlangsungan KBS berdasarkan jawaban responden yaitu diperlukan penambahan berbagai ragam souvenir Kebun Binatang Surabaya karena pengunjung merasa souvenir yang ada tidak menarik perhatian mereka. Contoh ragam souvenir yaitu benda yang dapat menarik minat pengunjung dan bermanfaat dikehidupan sehari-hari seperti cangkir, mangkok, topi, asbak, sendok, tumbler, atau benda lainnya. Membuat image baik pada Kebun Binatang Surabaya dengan meningkatkan pelayanan yang diberikan contohnya seperti penyediaan kotak saran sebagai bahan evaluasi yang belum ada di sekitar lokasi KBS, merenovasi bangunan dan wahana yang tersedia pada saat jam operasional tutup agar tidak mengganggu pengunjung. Meningkatkan fasilitas umum yang tersedia bagi pengunjung agar menjadi lebih baik dan nyaman digunakan. Menyelenggarakan event menarik dan dipublikasikan baik secara langsung ataupun lewat sosial media yang membuat masyarakat penasaran dan akhirnya berkunjung ke KBS. Serta selalu peka terhadap trend dan isu-isu terkait destinasi wisata yang ingin dan sering dikunjungi pengunjung agar KBS dapat bersaing dengan destinasi wisata lainnya.

Karena penelitian ini memiliki berbagai keterbatasan, untuk selanjutnya diharapkan dapat merubah atau memilih variabel lainnya yang dapat memengaruhi revisit intention seperti novelty-seeking, experiential quality, dan recreation benefit. Selanjutnya dapat memperluas cakupan wilayah dengan membandingkan destinasi wisata zoology lain karena penelitian ini hanya berfokus pada Kebun Binatang Surabaya. Penelitian ini berfokus pada pengunjung generasi muda (milenial) sehingga diharapkan penelitian selanjutnya dapat mencakup generasi lain yang datang ke Kebun Binatang Surabaya.

\section{DAFTAR PUSTAKA}

Assaker, G., Esposito, V., \& Connor, P. O. (2011). Examining the Effect of Novelty Seeking , Satisfaction, and Destination Image on Tourists ' Return Pattern: A Two Factor, Non-linear Latent Growth Model. Tourism Management, 32(4), 890-901. https://doi.org/10.1016/j.tourman.2010.08.004

Chen, C., \& Chen, F. (2010). xperience Quality, Perceived Value, Satisfaction and Behavioral Intentions for Heritage Tourists. Tourism Management, 31(1), 29-35. https://doi.org/10.1016/j.tourman.2009.02.008

Hajar, S., Taher, M., Jamal, S. A., Sumarjan, N., \& Aminudin, N. (2015). Examining the structural Relations among hikers' Assessment of Pull-Factors, Satisfaction and Revisit Intentions: The Case of Mountain Tourism in Malaysia. Journal of Outdoor Recreation and Tourism, 12(1), 82-88. https://doi.org/10.1016/j.jort.2015.11.012

Hartiana, T. I. P. (2014). Citra Perusahaan dalam Berita Krisis Perusahaan. Jurnal Kajian Komunikasi, 2(2), 126-137. https://doi.org/10.24198/jkk.vol2n2.3

Hasan, M. K., Abdullah, S. K., Lew, T. Y., \& Islam, M. F. (2019). The Antecedents of Tourist Attitudes to Revisit and Revisit Intentions for Coastal Tourism. International Journal of Culture, Tourism, and Hospitality Research, 13(2), 218-234. https://doi.org/10.1108/IJCTHR11-2018-0151

Higginbottom, K., \& Scott, N. (2015). Wildlife Tourism: A Strategic Destinayion Analysis. In Sustainable Tourism (pp. 35-53).

Indarwati, T. A., \& Tiarawati, M. (2015). Strategi Pemasaran melalui Experience dan Emotional 
Marketing terhadap Kepuasan dan Loyalitas Pelanggan di J.Co Donuts \& Caffee Surabaya. Jurnal Riset Ekonomi Dan Manajemen, 15(1), 102-117. https://doi.org/10.17970/jrem.15.150108.id

Irsyad, M., Hamid, D., \& Mawardi, M. (2017). Implementasi Strategi Pengembangan Wisata Kebun Binatang Surabaya sebagai Destinasi Wisata di Kota Surabaya. Jurnal Administrasi Bisnis S1 Universitas Brawijaya, 42(2), 59-66.

Jin, N. P., Lee, S., \& Lee, H. (2013). The Effect of Experience Quality on Perceived Value , Satisfaction, Image and Behavioral Intention of Water Park Patrons: New versus Repeat Visitors. International Journal of Tourism Research, 1(1), 1-14. https://doi.org/10.1002/jtr

Lee, M.-J., Chen, W.-X., \& Wu, W.-C. (2010). A Study of Tourist Destination Image, Satisfaction, Experiential Value and Revisiting Willingness. International Journal of Asian Tourism Management, 1(1), 13-29.

Li, L., \& Lee, L. (2016). Experiential Consumption and Customer Satisfaction : Moderating Effects of Perceived Values. International Journal of Marketing Studies, 8(5), 32-40. https://doi.org/10.5539/ijms.v8n5p32

Lin, M. T. (2019). Effects of Experiential Marketing on Experience Value and Customer Satisfaction in Ecotourism. Fondation Environmental Protection \& Research - FEPR, 28(107), 3151-3156.

Liu, J. T. (2016). Research On Taiwan Theme Parks' Experience Marketing Strategy and Revisit Willingness, Purchase Willingness and Recommendation Willingness. The International Journal of Organizational Innovation, 9(1), 35-53.

Loureiro, S. M. C., \& Gonzalez, F. J. M. (2013). The Importance of Quality, Satisfaction, Trust, and Image in Relation to Rural Tourist Loyalty. Journal of Travel \& Tourism Marketing, 25(2), 117-136. https://doi.org/10.1080/10548400802402321

Malhotra, naresh K., \& Birks, D. F. (2007). Marketing Research an Applied Approach. In P. Hall (Ed.), Aslib Proceedings (Original 3, Vol. 10). https://doi.org/10.1108/eb049676

Milman, A., \& Tasci, A. D. A. (2017). Exploring the Experiential and sociodemographic Drivers of Satisfaction and Loyalty in the theme Park Context. Journal of Destination Marketing \& Management, 1(1), 1-11. https://doi.org/10.1016/j.jdmm.2017.06.005

Musa, G., Mohammad, I., Thirumoorthi, T., Moghavvemi, S., \& Kasim, A. (2015). Exploring Visitors' Experience using Strategic Experiential Modules (SEMs): The Case of Zoo Negara, Kuala Lumpur. International Journal of Tourism Cities, 1(3), 234-253. https://doi.org/10.1108/IJTC-08-2014-0012

Prayag, G. (2013). Anatolia: An International Journal of Tourism and Image , Satisfaction and Loyalty - The Case of Cape Town. An International Journal of Tourism and Hospitality Research, 19(2), 37-41.

Prayag, G., Hosany, S., Muskat, B., \& Chiappa, G. Del. (2015). Understanding the Relationships between Tourists' Emotional Experiences, Perceived Overall Image, Satisfaction and Intention to Recommend. Joournal of Travel Reaserch, 1(1), 1-14. https://doi.org/10.1177/0047287515620567

Putri, D. A., Ramdlani, S., \& Martiningrum, I. (2015). Kebun Binatang Surabaya (Perancangan Ulang dengan Pengoptimalan Ruang Terbuka Hijau). Jurnal Mahasiswa Jurusan Arsitektur, 3(1), 112 . 
Viyo Tri Taraoktavia \& Tias Andarini Indarwati. Pengaruh Experiential Marketing dan Zoo Image terhadap Revisit Intention dengan Experiential Satisfaction sebagai Variabel Intervening

Saikim, F. H. B., Hamilton, J. R., Tee, S., \& Underdown, M. (2019). Wildlife Tourist Consumption in Sabah Malaysia: A SEM Path Model Approach. The 19th International Conference on Electronic Business, 12(8), 491-500.

Satvikadewi, A. A. . P., \& Kusumaningrum, H. (2019). Profil Psikografis \& Penggunaan Media pada Kelompok Milenial Pengunjung Kebun Binatang Surabaya. Jurnal Spektrum Komunikasi, 7(2), $15-28$.

Schmitt, B. (2013). Experiential Marketing. Journal of Marketing Management, 15(1), 53-67. https://doi.org/http://dx.doi.org/10.1362/026725799784870496

Surabaya, B. P. S. (2019). Kota Surabaya Dalam Angka 2019. In B. P. S. K. Surabaya (Ed.), Badan Pusat Statistik Kota Surabaya. Surabaya: CV. Azka Putra Pratama.

Tsaur, S., Chiu, Y., \& Wang, C. (2007). The Visitors Behavioral Consequences of Experiential Marketing The Visitors Behavioral Consequences of Experiential Marketing: An Empirical Study on Taipei Zoo. Journal of Travel \& Tourism Marketing, 21(1), 47-64. https://doi.org/10.1300/J073v21n01

W, R. W. A., Poluakan, M. V., Dikayuana, D., Wibowo, H., \& Raharjo, S. T. (2019). Potret Generasi Milenial Pada Era Revolusi Industri 4.0. Jurnal Pekerjaan Sosial, 2(2), 187-197.

Wang, W., Chen, J. S., Fan, L., \& Lu, J. (2012). Tourist Experience And Wetland Parks: A Case Of Zhejiang, China. Annals of Tourism Research, 39(4), 1763-1778. https://doi.org/10.1016/j.annals.2012.05.029

Wang, Y.-H., Wang, Y.-H., Chiu, J.-H., Liou, J.-Y., \& Yang, Y.-S. (2015). Recreation Benefit, Recreation Experience, Satisfaction and Revisit Intention-Evidence from Mo Zai Dun Story Island Department of Business Administration. Journal of Business \& Economic Policy, 2(2), $53-61$.

Wu, H.-C., Cheng, C.-C., \& Hong, W. (2017). An Assessment of Zoo Visitors' Revisit Intentions. Tourism Analysis, 22(3), 361-375. https://doi.org/10.3727/108354217X14955605216104

Wu, H.-C., Hong, W.-E., Chen, Y.-C., \& Wu, T.-P. (2016). Experiential Quality, Affective Commitment, Zoo Image, Novelty-Seeking, Experiential Satisfaction and Revisit Intentions. International Conference on Hospitality and Tourist Management, 4(1), 92-100.

Wu, H., Li, M., \& Li, T. (2018). A Study of Experiential Quality, Experiential Value, Experiential Satisfaction, Theme Park Image, and Revisit Intention. Journal of Hospitality \& Tourism Research, 42(1), 26-73. https://doi.org/10.1177/1096348014563396

Wu, H., \& Li, T. (2017). A Study of Experiential Quality, Perceived Value, Heritage Image , Experiential Satisfaction, and Behavioral Intentions for Heritage Tourists. Journal of Hospitality \& Tourism Research, 41(8), 904-944. https://doi.org/10.1177/1096348014525638

www.surabayazoo.co.id. 2018. Tentang PD. Taman Satwa KBS. (https://www.surabayazoo.co.id/index.php. Diakses pada 3 Maret 2020).

Yeh, T., Chen, S., \& Chen, T.-F. (2019). The Relationships among Experiential Marketing, Service Innovation and Customer Satisfaction-A Case Study of Tourism Factories in Taiwan. Sustainability MDPI, 11(1), 1-12. https://doi.org/10.3390/su11041041 